\title{
英語で授業する「日本文化・社会」コースに関連する日本語語彙の 導入の試み \\ Introducing Japanese Key Words and Expressions in 'Course of Japanese Culture and Society' Taught in English
}

\section{高橋 李 玉香 香港城市大学専上学院 語文學部}

\section{概要}

筆者は現在の勤務している香港城市大学専上学院語文学部で英語で「日本文化・社会入門コー ス」（Introduction to Japanese Culture and Society）を教えている。学習者は日本語・日本 研究を専攻している副学士課程の一年生(人数 合計 270 名)。日本語、日本文化が大好きとの理 由で入学している若い学生が多く占めている。このコースは必修科目で、英語で勉強している。香 港の大学教育方針により、語学関係以外の科目はすべて英語で行われる。その背景で、このコース を担当している筆者は英語で授業をしなければならない。週 2 時間のレクチャーでの使用言語、配 布資料、指定参考書などもすべて英語である。場合により、学生に日本語か中国語の補助教材を配 る。

本学にて多くの学生は文法、会話以外の日本文化と関連する語彙をたくさん覚えたい意欲が示さ れ、また 学生に興味を持たせるため、この授業にできるだけ、英語の配布資料に日本語の語彙も 並列して学習者に紹介する。筆者は英語の教材に適宜に授業テーマに関係している日本語語彙か言 い回しなどを取り入れたりする。例えば、日本の社会観念 (Social Concept) というテーマに「義 理」「人情」「本音」「建前」「甘え」のような日本独特的な語彙をハンドアウトに取り入れ、説 明する。アンケートで学生のフィードバックによれば、「漢字があって、分かり易い」、「英語よ り、漢字で難しい日本的な考え方を理解しやすい」、また「会話以外の日本語語彙が増え、よかっ た」、「日本文化に益々興味を持つようになった」などの声が多かった。

本稿では「日本文化・社会」の授業にて英語で教えながら、どのようにテーマと関連している日 本語の語彙、キーワードなどを授業内容に合わせて取り入れる試みについて紹介させていただきた いと思う。または、このような科目を教えるに何か新しいヒントを与えられたら嬉しいと思う。

キーワード :

ハード・ソフト文化、専門語彙、学習動機、義理、人情 


\section{用英語授課的「日本文化與社會」課堂導入日文關鍵辭彙的探討}

\section{高橋 李 玉香 香港城市大學專上學院 語文學部}

\section{1. 前言}

筆者現於香港城市大學專上學院語文學部以英語教授「日本文化與社會之入門課程」〔 Introduction to Japanese Culture and Society]。修讀日本語與日本文化副學士課程的一年生, 約有 270 人。對於年輕的學生來說, 修讀此副學士課程的最主要原因是：大多是對日本語及日本文化有著濃 厚的興趣。由於本課程必須以英語作爲授課語言, 依據本大學教學方針, 除了與語言學有關的科目外, 所有課程須以英語教授。在此前提下, 筆者於每週兩小時的大課〔Lecture 上, 所使用之語言、課程 資料、相關參考書等教材, 全部皆以英語作爲標準。然而, 在適當的情況下, 也會派發日文或中文版 本的補助筆記給學生, 讓他們對相關的課程內容有更深入的了解。

於授課期間, 爲使學生會更多會話以外的日本文化及社會相關詞彙、促使他們的學習態度更趨積 極, 筆者在此課程的英文講義上, 引入相關的日文漢字詞彙。講義的內容上, 如在介紹日本的社會觀 念 ( Social Concept) 爲題的課題上, 導入「義理」、「人情」、「本音」、「建前」、「甘え」等 日文獨有的漢字, 並對學生加以說明, 以使學生更易於理解。根據早前的問卷調查得知, 學生普遍認 爲, 「如於講義上附有漢字, 會比較簡單」及「與英文相比, 以日文漢字形式去思考會更易於理解」 另外, 大部份受訪的學生也表示「能夠學會日常會話以外的詞彙, 好極了」、「附有日文漢字的教材, 讓我對日本文化有著更濃厚的興趣」等意見。

本稿內容, 主要集中敍述如何在英文授課的課程內, 導入 $「$ 日本文化與社會」課程內容相關的詞 彙及其意義。筆者希望透過此稿, 能爲講授日本文化、社會及諸“事情'等課程提供一個講授新指標之餘, 也可提供另一加強學習日語詞彙的教授方法。

\section{2. 日本研究副學士課程}

本課程之目標: 首先是培養畢業生在各專業範圍內, 能純熟自如地運用日語。其次是讓他們能深 入了解日本社會及文化。另外, 同時也加強他們能運用中、英、日三語從事翻譯與傳意的工作。畢業 生能運用專業知識, 促進中日人士之間的文化和商業交流, 是本副學士的最大目的。

爲期兩年的副學士課程, 課程有日語文化結構、日語會話技巧、大學英語傳意技巧、商業日語、 觀光旅遊日語、日本歷史、日本文化和社會、中英日語翻譯和傳譯、現代日本透視及日本㸴究畢業論 文。而暑假期間，亦有暑期日本研修團文化交流活動等。 
一年級上學期之課程分類如下：

\begin{tabular}{|c|c|}
\hline Course Title & Credit \\
\hline $\begin{array}{c}\text { Structure of Japanese Language I } \\
\text { 日語結構 I }\end{array}$ & - \\
\hline $\begin{array}{c}\text { Japanese communication skills I } \\
\text { 日語傳意技巧 I }\end{array}$ & 4 \\
\hline $\begin{array}{c}\text { Introduction to Japanese culture and society } \\
\text { 日本文化與社會 }\end{array}$ & 2 \\
\hline $\begin{array}{c}\text { Listening strategies of Japanese Language I } \\
\text { 日本聽解 I }\end{array}$ & 2 \\
\hline
\end{tabular}

一年級下學期之課程分類如下：

\begin{tabular}{|c|c|}
\hline Course Title & Credit \\
\hline $\begin{array}{c}\text { Structure of Japanese Language II } \\
\text { 日語結構 II }\end{array}$ & 3 \\
\hline $\begin{array}{c}\text { Japanese communication skills II } \\
\text { 日語傳意技巧 II }\end{array}$ & 4 \\
\hline $\begin{array}{c}\text { Fundamentals of Japanese Reading and Writing } \\
\text { 日語閱讀書寫 }\end{array}$ & 2 \\
\hline $\begin{array}{c}\text { Listening strategies of Japanese Language II } \\
\text { 日語聽解 II }\end{array}$ & 2 \\
\hline
\end{tabular}

二年級上學期之課程分類如下：

\begin{tabular}{|c|c|}
\hline Course Title & Credit \\
\hline Practical Written Japanese I \\
日語文法書寫 I \\
\hline $\begin{array}{c}\text { Oral skills in Japanese I } \\
\text { 語會話 I }\end{array}$ & 3 \\
\hline $\begin{array}{c}\text { 觀光日語 } \\
\text { Japanese for Hospitality } \\
\text { 玳日本透視 }\end{array}$ & 3 \\
\hline $\begin{array}{c}\text { Selected Rearrent Affairs } \\
\text { 日本史 }\end{array}$ & 2 \\
\hline
\end{tabular}

二年級下學期之課程分類如下：

\begin{tabular}{|c|c|}
\hline Course Title & Credit \\
\hline $\begin{array}{c}\text { Practical Written Japanese II } \\
\text { 日文文法書寫 II }\end{array}$ & 3 \\
\hline $\begin{array}{c}\text { Oral skills in Japanese I } \\
\text { 日語會話 II }\end{array}$ & 3 \\
\hline $\begin{array}{c}\text { Business Japanese } \\
\text { 商業日語 }\end{array}$ & 4 \\
\hline $\begin{array}{c}\text { Trilingual Translation \& Interpretation (Japanese, } \\
\text { Chinese \& English) } \\
\text { 中、英、日語翻譯和傳譯 }\end{array}$ & 2 \\
\hline $\begin{array}{c}\text { Project } \\
\text { 日本硏究畢業論文 }\end{array}$ & 2 \\
\hline
\end{tabular}


高橋 李玉香：用英語授課的「日本文化與社會」課堂導入日文關鍵辭彙的探討

兩年間, 如能完成 60 個學分之課程便可畢業。其中與日本語、日本文化相關之科目佔 51 個學分, 剩餘 9 個學分則爲英語及心理學等相關課程。完成整個副學士課程後, 學生基本上已具備日本語能力 試 N3 或 N2〔2010 年所實施的日語水平新準則〕之日語程度。

而「日本文化與社會」〔Introduction to Japanese Culture and Society〕, 是每週 2 小時的必修入 門課程。在一個學期 13 個星期內, 主要是把日本文化及社會相關的知識介紹給本科生認識。課程內容 如下：

1) Explore Japan: Land and People (Geography and Climate)

《日本土地與日本人〔地理與氣候]》

2) Explore Japan: Food Culture, Housing and General Daily Life

《日本的飲食文化、住宅與生活》

3) Language, Communication and Society (Features of Interaction Skills)

《語言、溝通與日常對話技巧的特徵》.

4) A Brief History of Japan: From Ancient to Post-war

《日本史簡介：由古代至戰後》

5) Japanese Education: Current School Problems

《日本的教育制度：現今校園問題》

6) Japanese Social Ethics: Japanese Ways of Thinking

《日本人的倫理觀念與思維方式》

7) Japanese Working Culture and Japanese Labour Force

《日本的工作交化與勞動力》

8) Gender and Society: Marital Problems, Women Roles

《性別與社會：婚姻問題與女性地位》

9) Mid term test / Revision

中期測驗、復習

10) Japanese Life Course: Japanese Male, Women and Young People

《日本人的生活：男性、女性與年青人》 
11) Japanese Traditional Performing Arts

《日本傳統藝能》

12) Religion, Government, Political Economy

《宗教、政府、政治經濟》

13) Ikigai: Meanings of Life to Japanese?

《日本人的人生意義》

由於講授範圍大, 須於 13 個星期內, 把以上的課程向學生詳細解說, 實非易事。而且因時間限制, 亦無法進行小組討論。爲彌補這些不足, 於學期的末段, 學生須在這學期中所學習的內容中, 自行選 擇感想文的題目, 撰寫讀後感。

\section{3. 以英語講授日本文化、日本 “事情”的困難}

\section{（1）學生英語能力低下:}

近年香港學生英語水平較昔日學生低, 由於學生的英語能力不足, 授課全用英語時, 學生 在理解上有一定程度的困難, 所以在講授此課堂時, 筆者只使用百分之七十英語, 輔以百分之 三十廣東話, 並且引入與課題有關的日文專門用語〔keywords〕，幫助學生理解講授內容。 使用此方法授課之後, 不少學生均表示對課堂內容有深切理解。故全用英語時, 也許在理解某 些抽象觀念時, 出現問題。

\section{（2）授課節數時間少，但課程範圍大：}

本課程只有大課, 並沒有導修堂的時間。時間限制使我們無法導入小組討論的環節, 幫助 學生更深入了解課堂學習內容。換言之, 課堂上的知識傳授方式爲 : 單向 [一方通行) - 即是 講義由教師作主導, 學生依照老師所傳授的知識學習, 欠缺討論。這是因爲在課程學分編排上, 未能給予此節課多一些時間。欠缺小組討論是此課程的一大缺點。

\section{（3）學生與老師對「日本文化與社會」課程定義有偏差:}

老師在這門課中, 主要以學術和人類學的角度講授日本文化與社會中的軟文化〔肉眼看 不到, 屬內在思想〕和硬文化〔肉眼看到的〕, 並且同時也會講授歷史和宗教等複雜、蔇深 而具爭議性的議題。但是, 學生的日本文化與社會多爲：時裝、飲食、茶道、花道等肉眼上 可以看到的硬文化。故不少學生在使用英語學習此課堂時多表示希望能認識多些“硬件”式 的日本文化。 


\section{4. 提升學生對日本文化與社會的學習興趣之對策}

\section{（1）導入日文關鍵辭彙：}

兩年的課程內, 我們選用的教科書中, 以會話和文法爲中心。因此, 此等書籍內提及日本文化和 社會的詞彙甚少。現象尤見於一些新興或教科書裡沒有的詞彙, 如：「義理」、「人情」、「本音」、 $\ulcorner$ 建前」。因此, 在編集教材時, 爲使學生多認識日本文化的專有詞彙, 會導入與該課題相關的詞彙。 透過英語, 加上日文詞彙, 學生能有機會接觸多種語言, 提升他們的學習興趣。

如在第三課的課堂中, 透過播放歌曲的形式, 向學生介紹日本的方言。課堂上播放歌手夏川里美 小姐的一首充滿沖繩情懷的歌曲「涙そうそう」, 向學生解說沖繩方言的「そうそう」與標準方言

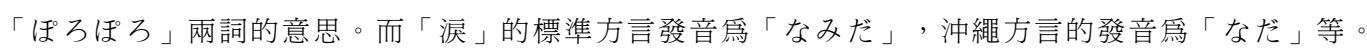
此曲的歌詞與旋律十分出色, 讓學生在理解方言上, 有顯著的效果。歌詞的內容如下:

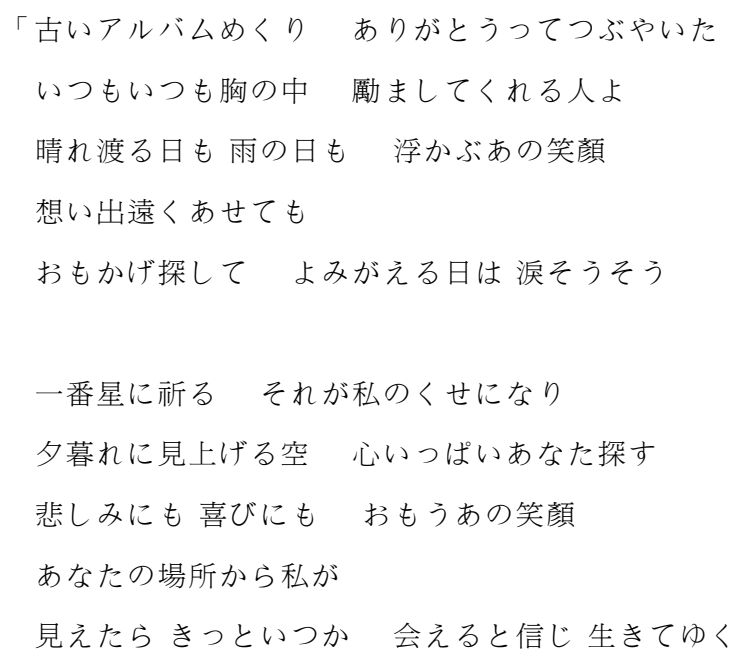

“Okinawa Best Song Collection” Teichiku Entertainment. INC. Japan TECE-25347. 
本課程共 13 節課, 導入日本文化及社會等相關詞彙共超過 360 個之多, 而各課題內容所使用的詞 彙，簡略介紹如下：

\begin{tabular}{|c|c|}
\hline 題目 & 主要的日文語彙 \\
\hline $\begin{array}{l}\text { 日本での年中行事 } \\
\text { 日本的傳統節日 }\end{array}$ & $\begin{array}{l}\text { 年中行事、成人式、節分、「鬼は外、福は内」、建国記念日、神武 } \\
\text { 天皇、ひな祭り、春分の日、緑の日、昭和天皇、憲法記念日、端午 } \\
\text { の節句、菖蒲湯、鯉のぼり、目の日、父の日、七夕、鿏牛、織姫、 } \\
\text { 仙台、宮城、短冊、海の日、湓、盆踊り、精霊流し、敬老の日、 } \\
\text { 中秋の名月、秋分の日、体育の日、文化の日、千歳飴、勤労感謝の } \\
\text { 日、明仁天皇、除夜の鐘、年越しそば }\end{array}$ \\
\hline $\begin{array}{l}\text { 日本教育とその問題点 } \\
\text { 教育制度與校園問題 }\end{array}$ & 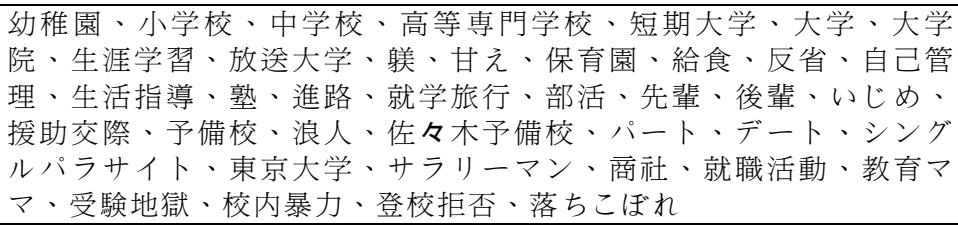 \\
\hline $\begin{array}{l}\text { 社会観念 } \\
\text { 社會觀念 }\end{array}$ & 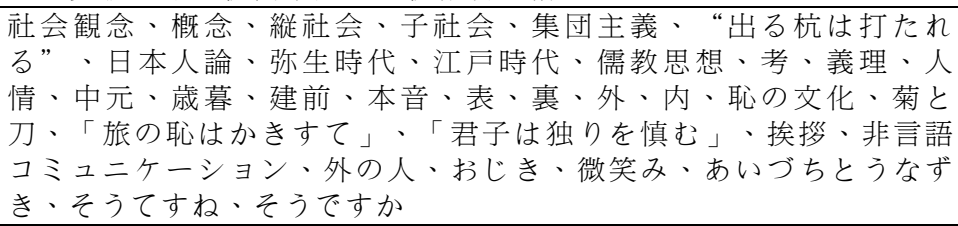 \\
\hline $\begin{array}{l}\text { 日本人の社会生活と行動 } \\
\text { 現代日本人的生活與生活 } \\
\text { 模式 }\end{array}$ & 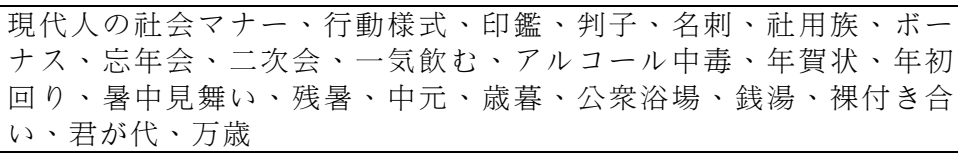 \\
\hline $\begin{array}{l}\text { 性別の役割と問題点 } \\
\text { 男女在日本社會上角色定 } \\
\text { 位與其問題 }\end{array}$ & $\begin{array}{l}\text { 紫式部、源氏物語、清少納言、枕の草子、孔子、徳川時代、紅灯 } \\
\text { 区、津田梅子、津田大学、吉岡弥生、東京女子医科大学、本塚雷 } \\
\text { 鳥、小林一三、専業主婦、女子、大生、家内、セックハラ、女性運 } \\
\text { 動、伝統社会、老人痴呆症、援助交際 }\end{array}$ \\
\hline $\begin{array}{l}\text { 男子、女子と若者の } \\
\text { ライフサイクル } \\
\text { 男性、女性及青年人的 } \\
\text { 生命周期 }\end{array}$ & $\begin{array}{l}\text { 奈良時代、平安時代、戦力結婚、仲人、夜ばい、お見合い、結納、 } \\
\text { 民法、家、課長、格差結婚、浮気、不倫、年金制度、社会保障、国 } \\
\text { 民健康保険、老齢年金、介護保険、婚活、草食系、乙メンンニー } \\
\text { ト、フリーター、腐女 }\end{array}$ \\
\hline $\begin{array}{l}\text { 日本人の生き甲斐 } \\
\text { 日本人的人生意義 }\end{array}$ & $\begin{array}{l}\text { 生き甲斐、定年、養老、入学、結婚、浪人、社会人、措見合い結 } \\
\text { 婚、恋結婚、仲人、適期、披露宴、浮気、不倫、離婚、核家庭 } \\
\text { 化、幏、厸壇、三世代同居、過労死、転勤、単身赴任、粗大ご } \\
\text { み、第二人生、熟年離婚、独身貴族、受験、登校拒否、御宅族 }\end{array}$ \\
\hline $\begin{array}{l}\text { 日本伝統文化 } \\
\text { 日本傳統文化 }\end{array}$ & $\begin{array}{l}\text { 歌舞伎、能、文楽、落語、生け花、舞楽、狂言、漫才、茶道、隈 } \\
\text { 取、時代物、世話物、所作物、国立劇場、歌舞伎座、中所、南座、 } \\
\text { 御園座、謡、囃子、世阿弥、幽玄、江戸時代、本狂言、間狂言、三 } \\
\text { 味線、落語家、家元、和清敬静、表千家、裏千家 } \\
\end{array}$ \\
\hline
\end{tabular}




\section{高橋 李玉香：用英語授課的「日本文化與社會」課堂導入日文關鍵辭彙的探討}

\section{（2）視㯖教材的運用：}

除了自編教材外, 課堂內也會導入視聽教材, 以增加授課時的趣味性。例如使用日本歌曲、雜 誌、漫畫、錄影帶、電視台綜藝節目、電影及劇集等, 向學生介紹日本最新資訊。爲配合授課內容範 圍, 筆者曾使用某電視台節目《ケンシンショー》介紹日本地理和飲食知識。該節目特意請來當地都 道府縣出生的娛樂藝人親身作介紹, 節目並附以日語字幕, 節目集視、聽於一身, 爲沉悶的課堂注入 一定程度歡樂與生氣。學生也可聆聽各地方言的日語。可達一石二鳥之效果。

\section{5. 運用視聽教材的效果與學生的感想}

大部分學生均表示, 導入日文詞彙後, 課堂的內容較沒有日文詞彙爲佳, 課堂有趣亦可提昇學生 學習動機。筆者發現學生上課時感覺疲乏的情況大減。老師生動有趣的講授方法能有助學生增加專注 力之餘, 也能拉近師生間的距離, 使課堂氣氛更趨融洽、和諧。問卷調查中有 $99 \%$ 的學生表示他們較 從前喜歡上課，又表示錄影帶、歌曲等等視聽媒介都使他們更了解日本文化和風土人情、認識更多日 本專有名詞及詞彙。同時亦有助他們日後自己閱讀日文文章等。

例如：「義理」、「人情」的概念, 學生一看漢字大概也可以估計箇中意義, 但如果只以英文標 音「giri」、「ninjo」表示的話, 學生會較難明白字詞的意思。有學生表示, 導入日文詞彙後, 他們能 從課堂中學到一些教科書或書本中學不到的課外詞彙或表達日本文化社會觀念的專門用語。大部分學 員頗感滿意。日本詞彙能夠促進他們的學習動機, 更希望學生的成績能夠因此有所提升。

此外, 日文詞彙也能加強他們對日本文化的興趣之餘, 又可協助他們進一步了解日本文化。學生 認爲以英語來學習這門課的話, 會大大減低他們的學習興趣。原因是：日本的官方語言是日本語, 不 是英語。當大家在課堂講義中看到日文漢字, 會聯想到自己的母語 一 中國語。因此, 學生在這門課中 也不其然找到英文所不能取代的親切感。

\section{6. 問卷調查的結果}

於 2009 年 11 月, 以英語問卷方式, 訪問了 160 名學生。收集了 152 名學生〔 $98 \%$ 對導入日語 關鍵詞彙的意見。此問卷調查顯示「日本文化與社會」課程頗受學生歡迎，並且發覺導入日語關鍵詞 彙的方法, 使學生成績有顯著的提升。

根據學生的意見，可歸納爲以下各點：

- $「$ 課堂變得更爲有趣」;

- $「$ 能夠學到更多課堂以外的知識」;

- 「令沉悶的課程內容變得易於理解, 令人興奮」; 
- 「此方法能提升學習的效果」;

- 「因有日語的詞彙, 令講義內容更爲豐富, 也易於理解」;

- 「導入日文關鍵詞彙的講義內容易於記憶之餘, 有利於考試測驗時作答問題」;

- 「縱然英文的水平不高, 因有日文關鍵詞彙的幫助, 也能推敲字詞當中的意思」。

\section{問卷調查之樣本如下：}

LS12805 Introduction to Japanese Culture and Society

Survey on "Japanese Keywords you have learned in the Lecture"

Conducted by: Dr. Rita Takahashi

Survey Purpose: In the handouts given and distributed in lectures of this course, you may find that there are a number of Japanese keywords, expressions printed along side the English teaching materials to help you get a better understanding of the course content. Meanwhile, it is also our purpose to give you more exposure to Japanese vocabularies which are pertaining to each topic in the lecture to help deepen your understanding of Japanese culture and society.

Please kindly give your comments in the following blanks: circle your answers by inserting $1,2,3,4,5$ to indicate the ranking of importance, 1 is the lowest, 5 is the highest:

1) How do you evaluate the keywords given in the lectures:

( ) - you enjoy learning it as it can increase you words / vocabulary power

( ) - learning Japanese keywords on Japanese culture and society is useful and practical to deepen your understanding of Japanese culture, people and society

( ) - it can arouse my interest to learn and to know more about Japanese culture and society as Japanese "Kanji" is very impressive and easy to understand its meaning 
( ) - I can guess the meaning of Japanese Kanji 日本の漢字 as they look similar to that of the Chinese Kanji 中国の漢字

( ) - if there are only English keywords, I may find it difficult to guess or to understand the real meaning and essence of Japanese culture and society

Any other comments:

You may express your comments freely (good, interesting, helpful, difficult, or useless etc)

\section{結語}

以英語教授的「日本文化與社會入門課程」, 於講課內容上導入與課程內容相關的日文關鍵辭 彙, 除有助學生學習本課程內容外, 學生亦可從日文漢字的層面, 去了解《日本文化與社會》課程的 專門概念, 可令他們易於理解當中的深層意義外, 學生也可從中找到英文所不能取代的親切感, 以增 強他們的學習興趣。

\section{參考資料}

致良日語工作室編訳、「日本剖析」 台湾：致良出版社 1998

韓立紅 編著「日本文化概論」天津 南開大学出版 2003

本名信行、ベイッ・ホッファ編「日本文化を英語で説明する辞典」東京：有斐閣 1986

板坂元監修「英語で話す日本の謎」東京：講談社 1996

Clark, Scott. Japan, A View from the Bath. Hawaii: University of Hawaii Press, 1994

Cortazzi, Hugh. A Concise Survey Modern Japan. Tokyo: The Japan Times, 1994

Hendry, Joy. Understanding Japanese Society. London and New York: Routledge, 1992

Hicks, George. Japan's Hidden Apartheid: The Korean Minority and the Japanese. Aldershot: Ashgate Publishing Limited, 1997

Vogel, Ezra F. Japan As Number 1 Philadelphia: Harper Torchbooks, 1985 


\section{附錄}

以下爲部份 $\ulcorner$ 日本文化與社會」課程之講義, 以供參考之用：

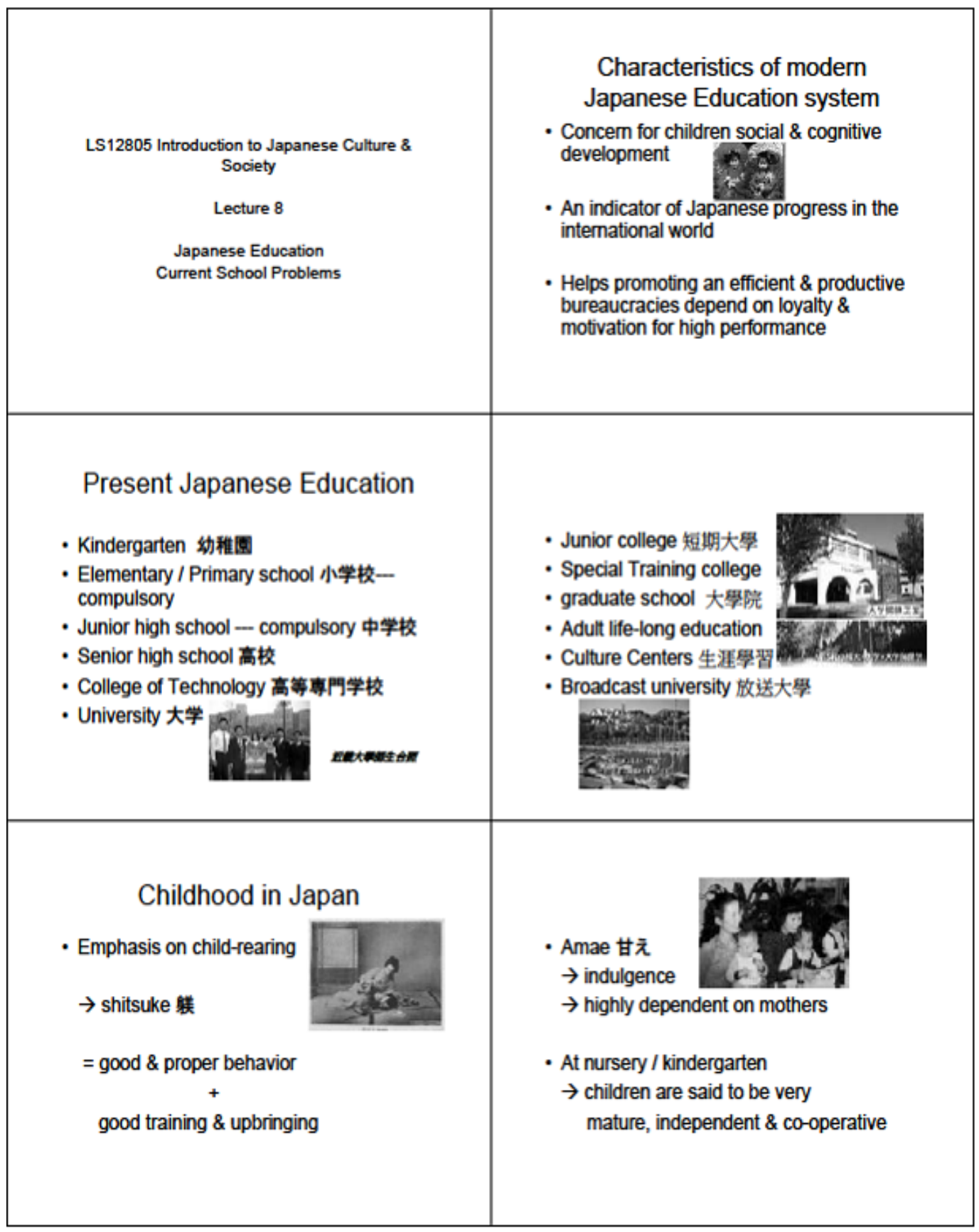


- At home

- Japanese mothers have to give more:

1. understanding

2. love \& patience to children

$\rightarrow$ Children are expected to be: helpful, independent \& co-operative outside school

$\rightarrow$ Children can enjoy Amae $甘 \dot{z}$ at home

$\rightarrow$ Exert co-operative character outside

\section{Pre-school education}

- Pre-school education

= Nursery school + kindergarten + family education

- Aged 2-4 : Nursery centers 保育園

- Aged 4-5: Kindergarten 幼稚園

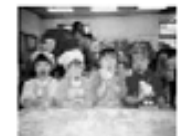

- Learn social activity

- Concern for others

- Group play

- Teachers let children to fix the problems themselves

$\rightarrow$ Academic learning $X$ $\rightarrow$ Playing, fun \& group consciousness $O$

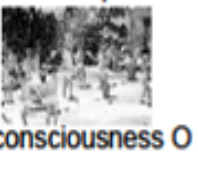

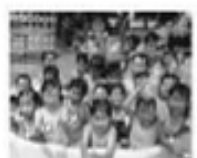

\section{Elementary school}

- Continuing focus of:

$\rightarrow$ social attitudes \& self-restraint

$\rightarrow$ whole person development i.e. PE lesson

$\rightarrow$ character building

- Academic performance $X$

- NO English teaching

- International understanding classroom time
- Public schools offer lunch 给食

- Students are required to be: $\rightarrow$ independent \& enthusiastic $\rightarrow$ mentally \& physically strong

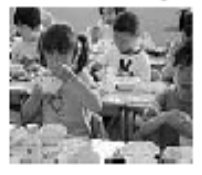

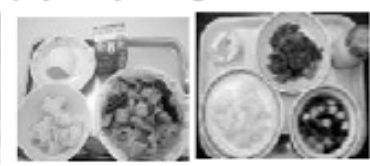

- Teachers will visit children's family

- Class meeting with parents at regular time in academic years

- Moral education emphasizes:

$\rightarrow$ Reflection 反省(はんせい)

$\rightarrow$ self-management 自己管理(じこかんり) 


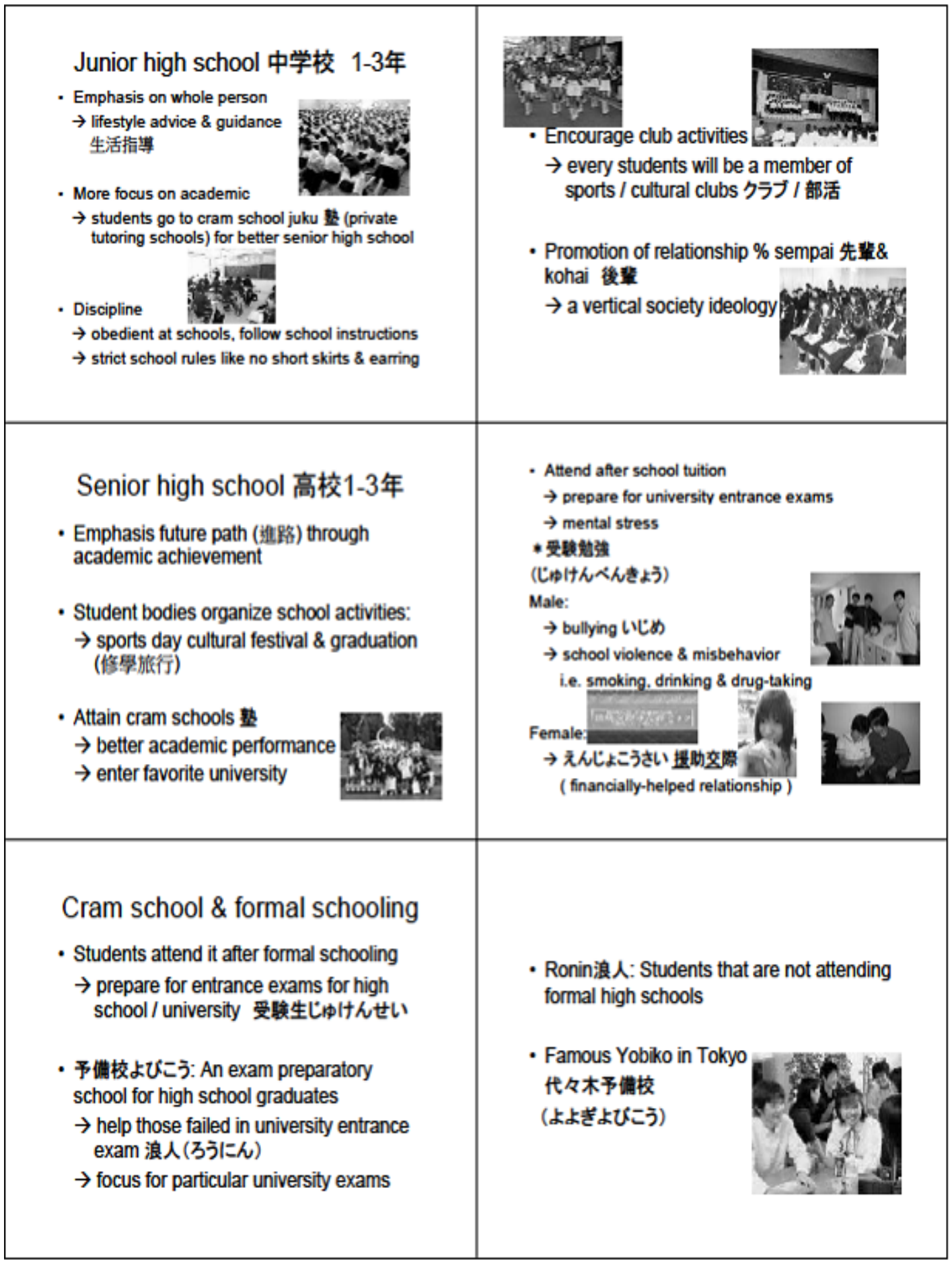




\begin{tabular}{|c|c|}
\hline $\begin{array}{l}\quad \text { University Education } \\
\text { - Japanese university } \\
=\text { paradise / leisure land for students } \\
\text { - Difficult to enter: graduate with ease } \\
\text { - Two slogans: } \\
\text { Pa-to パート part-time job } \\
\text { De-to テーート date }\end{array}$ & $\begin{array}{l}\text { - Part-time job OOO } \\
\text { - Academic learning XXX } \\
\rightarrow \text { no studying is needed in some sense } \\
\text { - Criticized teaching methods: } \\
\text { boring, stagnant \& conservative } \\
\text { - University graduates = elite in society } \\
\end{array}$ \\
\hline $\begin{array}{l}\text { • Many youngsters do not marry \& } \\
\text { stay with their parents } \\
\text { シングルバラサイト } \\
\text { (spend money } \mathrm{X} \text { ) (enjoy freedom O) } \\
\text { - but lack of social responsibility \& } \\
\text { social consciousness }\end{array}$ & $\begin{array}{l}\text { Education \& Employment } \\
\text { - Important path for social success \& mobility } \\
\text { - Government officials are graduates from } \\
\text { famous public / private universities } \\
\text { - Tokyo university } \\
\text { 東京大学 } \\
\rightarrow \text { the top national } \\
\text { university } \\
\rightarrow \text { produce top government } \\
\text { officials \& top management elite }\end{array}$ \\
\hline $\begin{array}{l}\text { - Big enterprises \& companies usually } \\
\text { employ famous universities graduates } \\
\rightarrow \text { trust elite from top universities } \\
\text { - Education achievement = career success } \\
\text { - University graduates prefer to work for big } \\
\text { companies as salaryman サシリーマン or in } \\
\text { trading / commercial firms 商社マン } \\
\text { - The employment activity 就職活動 } \\
\text { (就活 ) for } 4^{\text {th }} \text { year undergraduate } \\
\text { students }\end{array}$ & 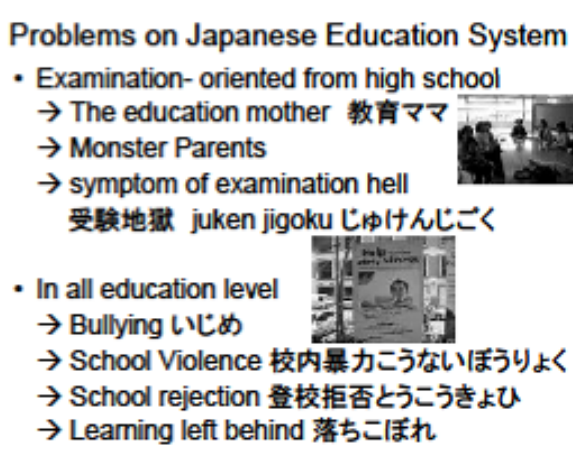 \\
\hline
\end{tabular}




\section{General assessment}

- Highly evaluated in Japan

$\rightarrow$ success to create an well-educated, well-trained working force for.

society, commercial \& bureaucratic sectors

- Poorly evaluated from Western

$\rightarrow$ too much emphasize on academic performance by conformity rote memorization

$\rightarrow$ stifling of:

individuality, creativity \& initiative-ness 